\title{
GUANTANAMERA, O FILME: INTERCULTURALIDADE E INCLUSÃO NO ENSINO DE CULTURAS E LITERATURAS HISPÂNICAS
}

\author{
GUANTANAMERA, THE MOVIE: INTERCULTURALITY AND \\ INCLUSION IN THE TEACHING OF HISPANIC CULTURES AND \\ LITERATURES
}

Amarino Oliveira de Queiroz*

\begin{abstract}
Resumo: O presente estudo buscar verificar de que forma a articulação entre as poéticas da oralidade e a arte cinematográfica pode configurar, dentro do contexto da sala de aula, uma ferramenta pedagógica intercultural inclusiva. Apoiados conceitualmente na perspectiva da Interculturalidade apresentada por Catherine Walsh (2005), entre outros autores, tomaremos como ponto de partida o filme cubano Guantanamera, realizado em 1995 pelos cineastas Tomás Gutiérrez Alea e Juan Carlos Tabío. Destacaremos na análise do seu processo narrativo a utilização da guajira, gênero lírico-musical criollo originário da ilha de Cuba, bem como a inserção do pataki, também referido como itan, relato sagrado da tradição oral afro-cubana, dois elementos fundamentais acionados pelos diretores na diegese da obra em questão e aqui tratados como possível recurso didático auxiliar no desenvolvimento das aulas de culturas e literaturas hispânicas.
\end{abstract}

Palavras-chave: Literatura. Cinema. Interculturalidade.

\begin{abstract}
The present study seeks to verify how the articulation between the poetics of orality and the cinematographic art can configure, within the context of the classroom, an inclusive intercultural pedagogical tool. Conceptually supported by the perspective of Interculturality presented by Catherine Walsh (2005), among others, we will take as a starting point the Cuban film Guantanamera, made in 1995 by the filmmakers Tomás Gutiérrez Alea and Juan Carlos Tabío. We will emphasize in the analysis of its narrative process the use of guajira, lyrical-musical creole genre from the island of Cuba, as well as the insertion of pataki, also referred to as itan, a sacred oral account of the Afro-Cuban tradition, two fundamental elements triggered by the directors in the diegesis of the presented work and here treated as possible auxiliary didactic resource in the development of the classes of hispanic cultures and literatures.
\end{abstract}

Keywords: Literature. Cinema. Interculturality.

\section{Introdução}

De definição abrangente, o conceito de narrativa circula em diferentes áreas do conhecimento humano a exemplo da literatura e do cinema, podendo identificar, em ambos os casos, uma caracterização recorrente: a tentativa de nomear e tipificar aspectos relativos à criação e ao desenvolvimento de uma história que se pretenda contar.

Um entendimento da narrativa literária implicaria, em linhas gerais, na apresentação de uma história narrada verbalmente enquanto criação na oralidade, consumida por um público ouvinte, bem como através de meio impresso, no caso das criações ficcionais desenvolvidas em modalidade escrita e remetidas a um público

\footnotetext{
* Professor da Universidade Federal do Rio Grande do Norte - Departamento de Letras do Centro de Ensino Superior do Seridó- CERES - Currais Novos -amarinoqueiroz@ yahoo.com.br
} 
leitor. Diferentemente da narrativa escrita, com a sua "baixa iconicidade e a sua elevada função simbólica", a narrativa fílmica apresenta uma dimensão icônica "mais evidente e mais dominante do que na literatura" (BELLO, 2001, p. 84).

Em Literatura e Cinema: elo e confronto (2010, p. 210), estudo que discute a nível teórico as relações entre as ambas as linguagens, Linda Catarina Gualda observa que, se na primeira há uma representação de imagens, um encadeamento de ideias (imagens) básicas, partindo da palavra para chegar à imagem visiva, no segundo há uma reprodução de imagens, uma sequência de imagens mentais mediante imagens sonoras e não sonoras, partindo da imagem visiva para chegar à expressão verbal.

Na perspectiva de Sarmento, ambas as linguagens são, porém,

independentes e autônomas em suas naturezas e histórias, com reconhecimentos e trajetórias específicos, recebem influxo da evolução das demais artes e incorporam influências que receberam de outras manifestações artísticas. Consequentemente literatura e cinema acabaram por encontrar-se e de alguma forma modificaram-se mutuamente. (SARMENTO, 2012, p. 5)

Ainda de acordo com Sarmento (2012, p. 6), a arte cinematográfica teria como segunda natureza a vertente literária, por trazer em seu bojo o processo narrativo da literatura, mesmo que em sentido inverso, "numa lógica contrária, posto que aquilo que na literatura é visado como efeito (a imagem), no cinema é dado como matéria narrativa".

O cinema, no entanto,

dominou e potencializou os efeitos da literatura na construção do imaginário coletivo do século XX, com recursos tecnológicos que cativaram massas de espectadores transpondo tempos e espaços, alcançando uma dimensão além do até então possível pela literatura.

(...)

Ao contrário do que geralmente se pensa, o filme não matou a literatura, a transformou em aliada, fazendo dela sua principal fonte de inspiração, tendo assim, de forma inexorável, construído um devir entre essas duas linguagens numa dialética na qual transformações e construções estruturais foram mútuas e provocadas justamente por esta dialética. (SARMENTO, 2012, p. 7)

Pensando então no vasto diálogo entabulado entre a literatura e o cinema nos mais variados contextos culturais, bem como em possíveis desdobramentos relativos à utilização das duas estéticas com uma finalidade pedagógica, apresentaremos uma questão inicial: de que forma associações entre poéticas e narrativas da oralidade e arte cinematográfica poderiam configurar a título de exemplo - e no contexto da sala de aula - uma ferramenta pedagógica intercultural inclusiva? 


\section{Interculturalidade, literatura e cinema}

$\mathrm{Na}$ tentativa de sinalizar uma resposta plausível, recorreremos ao filme cubano Guantanamera, dirigido por Tomás Guitérrez Alea e Juan Carlos Tabío em 1995, nele destacando a ocorrência de dois elementos narrativos incorporados à diegese da obra: a poética-musical da guajira, ou punto cubano, e a narrativa tradicional afro-cubana representada pelo pataki, que trataremos de descrever mais adiante.

$O$ viés analítico adotado parte da perspectiva conceitual em torno da interculturalidade e dialoga com o pensamento de autores e autoras como Néstor García Canclini (2003) e Catherine Walsh $(2005,1998)$, para quem a interculturalidade pode ser pensada como

un proceso de relación, comunicación y aprendizaje entre personas, grupos, conocimientos, valores y tradiciones distintas, enfocado en generar, construir y propiciar un respeto mutuo y un desarrollo plenos de las capacidades de los individuos, a pesar de sus diferencias culturales, sociales y de género.

Es un proceso que intenta romper con la historia hegemónica de una cultura dominante y otras subordinadas y, de esa manera, reforzar las identidades tradicionalmente excluidas para construir, en la vida cotidiana, una convivencia de respeto y de legitimidad entre todos los grupos de la sociedad.

La base de la interculturalidad es la identidad, la identidad individual, de los diversos grupos socioculturales y de la sociedad. (WALSH, 1998, pp. 119120).

Aspectos como os acima descritos, que além de investir numa ruptura das hegemonias culturais reforçam e legitimam as identidades tradicionalmente excluídas serão evidenciados através da narrativa pluralizada que dá forma ao filme cubano Guantanamera, cuja sinopse informa tratar-se de uma

\footnotetext{
Comedia satírica sobre la vida en Cuba. Un atípico cortejo fúnebre y un camión siguen la misma ruta. El cortejo, compuesto por un funcionario, su esposa Gina y un anciano enamorado de la difunta, debe cumplir un nuevo y ahorrativo plan estatal de traslado de difuntos.

En el camión van Mariano, un seductor empedernido, y Ramón, su más fiel aliado. Mariano y Gina se reconocen: él fue alumno de Gina en la Universidad y se enamoró de ella.

Mientras el cortejo fúnebre y el camión avanzan, se producen un sinfín de divertidas peripecias que van uniendo poco a poco a Gina y a Mariano hasta que, por fin, toman una decisión. (FILMAFFINITY, s.d) ${ }^{1}$
}

$\mathrm{Na}$ arte cinematográfica, assim como em outros produtos culturais, costuma-se dizer que algo é diegético quando ocorre dentro da ação narrativa ficcional do próprio filme. Em Guantanamera, uma relação intercultural se produz pela inserção de dois elementos característicos da tradição oral cubana incorporados pelos diretores à

\footnotetext{
${ }^{1}$ Sinopse do filme disponivel em: https://www.filmaffinity.com/es/film944543.html
} 
composição do seu processo narrativo, nomeadamente a guajira crioula e o pataki afrocubano.

\title{
2 A guajira e o pataki
}

De acordo com Antonio Gómez Sotolongo (2016, p. 148) a palavra guajiro ou guajira foi utilizada durante o século XVI para nomear os aborígenes escravizados que os espanhóis levaram para Cuba, procedentes da Península de la Guajira, atual território colombiano. Mais tarde, o termo viria a ser utilizado como sinônimo de camponês.

Primeiro dos dois procedimentos constitutivos da narração utilizados alternativamente pelos diretores ao longo do filme, a guajira consiste num gênero lírico-musical de origem criolla, ou seja, um herança da colonização española, sendo geralmente estruturado em décimas.

De "Guajira Guantanamera", canção evocada no filme, sabe-se que a melodía foi composta em 1944 e atribuída oficialmente a José Fernández Días, o Joseíto, embora tenha ficado internacionalmente conhecida através da adaptação feita por Julián Orbón sobre os "Versos Sencillos" do poeta e herói nacional cubano José Martí. De modo diferenciado à tradição da guajira, os versos do poema de Martí adaptados à canção foram majoritariamente estruturados em quartetos. São de Martí os fragmentos parcialmente reproduzidos a seguir:

\author{
Yo soy un hombre sincero \\ De donde crece la palma, \\ $\mathrm{Y}$ antes de morirme quiero \\ Echar mis versos del alma. \\ Mi verso es de un verde claro \\ Y de un carmín encendido \\ Mi verso es un ciervo herido \\ Que busca en el monte amparo. \\ Con los pobres de la tierra \\ Quiero yo mi suerte echar. \\ El arroyo de la sierra \\ Me complace más que el mar.
}

(MARTí, 2016, pp. 128)

Já nas cenas iniciais do filme uma voz narradora em off inicia o relato cantado, conduzindo a história no ritmo da guajira. Este procedimento vai se repetir em outros momentos, alternando-se ao desenvolvimento das falas $\mathrm{e}$ das cenas que, harmoniosamente, dão conta do fluxo diegético, estabelecendo um rico diálogo entre discurso poético-musical e imagens em movimento.

A segunda das criações na oralidade utilizada na construção narrativa de Guantanamera é o gênero conhecido em Cuba como Pataki ou Patakí, que corresponde às narrativas sagradas da Regla de Osha ou Santería, "denominação genérica e não ortodoxa da tradição religiosa resultante da aproximação dos cultos iorubanos com o catolicismo" (LOPES, 2004, p. 602).

O pataki está caracterizado na forma de relatos curtos que fazem parte da cosmogonia afro-cubana e configuram, portanto, o conjunto de mitos e lendas sagradas 
da religião lucumí ou iorubá em Cuba. Trata das histórias dos Orishas, contando ou explicando muitas das características, poderes ou funções dessas divindades. Nesses relatos são descritas as origens dos deuses, suas relações e os diversos papéis que desempenharam na criação do mundo e da humanidade, trazendo sempre uma mensagem de fundo.

No caso de Guantanamera, o recurso ao pataki "La muerte de la inmortalidad (Olofin, Iku y el fin de la inmortalidad) desempenha uma função enunciadora estratégica, funcionando como uma espécie de metáfora da morte e da necessidade de transformação da vida, o que pode ser interpretado como um posicionamento crítico dos diretores frente à crise social, econômica e instititucional que o país enfrentava naquela altura.

$\mathrm{Na}$ cosmogonia afro-cubana de matriz iorubana ou lucumí, Olofin representa "um ser incriado", a "personificação de tudo que é o divino, causa e razão de todas as coisas", "aquele que se relaciona diretamente com os Orixás e os homens" (LOPES, 2044, pp. 495-496). Iku, por sua vez, é a representação da Morte, "divindade superior, encarregada de privar da vida as pessoas, arrebatando seu espírito" (LOPES, 2004, p. 337).

Pela importância que esta modalidade de relato oral assume na narrativa fílmica em questão, disponibilizaremos a seguir a sua transcrição integral:

\begin{abstract}
Al principio del mundo, Olofin hizo al hombre y a la mujer y les dio la vida. Olofin hizo la vida pero se le olvidó hacer la muerte.

Pasaron los años y los hombres y las mujeres cada vez se ponían más viejos, pero no se morían. La Tierra se llenó de viejos que tenían miles de años y que seguían mandando de acuerdo con sus viejas leyes.

Tanto clamaron los más jóvenes que un día sus clamores llegaron a oídos de Olofin. Y Olofin vió que el mundo no era tan bueno como él lo había planeado. Y sintió que él también estaba viejo y cansado para volver a empezar lo que tan mal le había salido.

Hizo Iku entonces que lloviera sobre la Tierra durante treinta días y treinta noches sin parar y todo fue quedando bajo el agua.

Sólo los niños y los más jóvenes pudieron treparse en los árboles gigantes y subir a las montañas más altas.

La Tierra entera se convirtió en un gran río sin orillas.

Los jóvenes vieron entonces que la Tierra estaba más limpia y más bella. Y corrieron a darle gracias a Iku, porque había acabado con la inmortalidad. ${ }^{2}$
\end{abstract}

Conforme anunciávamos anteriormente, essa "morte da imortalidade" descrita através do pataki pode sugerir, inclusive, um estratégico aceno dos realizadores em face da emergência de mudanças políticas que já se esboçava no gerenciamento da ilha. Assim sendo, momentos como o da chuva intensa que cai sobre o cemitério na hora da leitura do discurso de despedida pode funcionar, aos olhos do espectador, como uma espécie de metáfora da transformação:

En uno de los momentos finales del filme, escuchamos una voz en off que narra un mito africano (...) que viene a relacionar la lluvia con la muerte y la

\footnotetext{
${ }^{2}$ Transcrito de Paul A. Schroeder em Tomás Gutiérrez Alea. The Dialectics of a Filmaker. Nueva York: Routledge, 2002.
} 
purificación que hace que los más ancianos dejen paso a las nuevas generaciones.

(...)

Si interpretamos de esta manera la inclusión del mito en la película, que mucha polémica ha suscitado, el mensaje gana fuerza con el paso de los años. (GIMÉNEZ; BALDOVÍ; DÍAZ, 2017, en línea) ${ }^{3}$

\section{Considerações finais}

A leitura do filme Guantanamera aquí empreendida buscou estabelecer uma relação diferenciada entre literatura e cinema, privilegiando uma perspectiva além dos estudos comparados que tratam da transposição das obras literárias para a linguagem cinematográfica.

$\mathrm{O}$ recurso à pluralidade de linguagens narrativas adotado pelo filme, alinhando oralidade, iconicidade, expressão escrita, tradição, contemporaneidade, cinema, literatura e música, estabelece um proceso dialógico, dinâmico, interativo e crítico que desestabiliza pretensas hierarquizações discursivas.

Atentos à perspectiva inclusiva das negociações interculturais sinalizadas através das formulações de Catherine Walsh (1998), entre outros pensadores e pensadoras, assistimos em Guantanamera a um intercâmbio cultural produzido em condições de igualdade, onde experiências diversas são acionadas num processo de interação entre pessoas, conhecimentos e práticas culturalmente diferentes, conforme sugerido pelo diálogo desenvolvido entre a guajira e o pataki com a arte cinematográfica.

Este poderia ser um ponto de partida para que se colocasse em prática uma ação pedagógica comprometida com e voltada para a diversalidade, na acepção do termo sugerida por Walter Mignolo (2003) e retomada por Adelia Miglievich-Ribeiro (2014): citando textualmente o pensador argentino e suas considerações críticas em torno da realidade pós-colonial, Miglievich-Ribeiro (2014b, p. 157) assinala que Mignolo propõe um novo horizontes de saberes, por ele identificado como "pensamento liminar". Essa estratégia se definiria como uma atitude descolonizadora, "a articular a história universal como "diversalidade", evidenciando os contextos singulares, suas fraturas, tensões, assimetrias, conflitos, hibridizações”.

E ao discorrer propositivamente sobre os desafios ético-político-epistemológicos à cosmovisão moderna, a socióloga carioca também chama a atenção para

a urgência do diálogo a partir do Sul entre as distintas esferas culturais bem como da ação descolonizadora das subalternidades mediante a ênfase nas experiências singulares, na tradução e na articulação das diferenças em torno de projetos plurais de reconhecimento de sujeitos e suas vozes para a ampliação do universal como diversalidade [uma vez que]

A revisão das epistemologias modernas impõe-se como desafio teórico para a inteligibilidade do mundo em sua hibridez; também como desafio ético e

\footnotetext{
3 "La crisis de la Revolución Cubana en el cine. 'Guantanamera'. En: Cinéfalos Noctámbulos, 02 ago 2014. Disponible en: https://cinefagosnoctambulos.wordpress.com/2014/08/02/la-crisis-de-la-revolucioncubana-en-el-cine-guantanamera/ Aceso en: 26 abr 2017.
} 
político, na medida em que explicita a exclusão e o silenciamento de sujeitos levados à desumanização, tendo seus saberes e cosmovisões negados como explicativos e orientadores legítimos de condutas. (MIGLIEVICH-RIBEIRO, 2014, p. 66)

Pelo seu caráter propositivo, iniciativas como a que acabamos de descrever certamente poderão consistir numa importante estratégia pedagógica, alavancando não apenas a elaboração de materiais didáticos voltados especificamente para o ensino de língua, culturas e literaturas hispânicas ,como também promovendo a continuidade de um necessário e inadiável debate teórico-crítico-reflexivo em torno da descolonização do pensamento.

\section{Referências}

BELLO, M. R. L. L. Narrativa literária e narrativa fílmica: o caso de Amor de Perdição. Lisboa: Fundação Calouste Gulbenkian, 2001.

CANCLINI, N. G. Culturas Híbridas: Estratégias para Entrar e Sair da Modernidade. $2^{\circ}$ ed., São Paulo: Editora da Universidade de São Paulo, 2003.

CRUZ, G. R. Oralidad africana en Cuba: memoria y discurso de permanencia cultural. In: Revista Oráfrica 2, Barcelona: CEIBA, 2006, pp. 113-129.

FILMAFFINITY. Sinopsis de la película Guantanamera. Disponivel em: https://www.filmaffinity.com/es/film944543.html Acessado em: 26 abr 2017.

GIMÉNEZ, D.; BALDOVÍ, D.; DÍAZ, I. "La crisis de la Revolución Cubana en el cine. 'Guantanamera'. En: Cinéfalos Noctámbulos, 02 ago 2014. Disponível em: https://cinefagosnoctambulos.wordpress.com/2014/08/02/la-crisis-de-la-revolucioncubana-en-el-cine-guantanamera/ Aceso en: 26 abr 2017.

GUALDA, L. C. "Literatura e Cinema: elo e confronto". In: Revista Matrizes Ano 3 $n^{\circ}$ 2. São Paulo: USP, jan./jul. 2010.

GUANTANAMERA. Direção: Tomás Gutierrez Alea e Juan Carlos Tabío. Cuba/ Espanha/ Alemanha: Alta Films; ICAIC; Prime Films; Road Movies Dritte Produktionen; Tornasol Films, c1995. 1 DVD (105 min), colorido.

LOPES, N. Enciclopédia Brasileira da Diáspora Africana. São Paulo: Selo Negro, 2004.

MARTÍ, J. "Versos sencillos. In: Obras completas - Edición crítica. Poesia (vol.1). La Habana: CEM - Centro de Estudios Martianos - CLACSO, 2016.

MIGLIEVICH-RIBEIRO, A. "Por uma razão decolonial: Desafios ético-políticoepistemológicos à cosmovisão moderna". In: Revista Civitas V. 14, N. 1. Dossiê Diálogos do Sul. Porto Alegre: PUC-RS, jan-abr 2014, pp. 66-80. 
MIGLIEVICH-RIBEIRO, A. "O pensamento crítico acerca da universidade na América Latina: de Darcy Ribeiro à "modernidade-colonialidade". In: Revista de Estudos \& Pesquisas sobre as Américas - Dossiê Especial: Pensamento e Teoria nos Estudos Latino-americanos. V.8 N.2. Brasília: UnB - CEPPAC, 2014b, pp. 149-164.

MIGNOLO, W. Histórias locais / projetos globais. Colonialidade, saberes subalternos e pensamento liminar. Tradução de Solange Ribeiro de Oliveira. Belo Horizonte: Editora UFMG, 2003.

OLOFIN, IKU Y EL FIN DE LA INMORTALIDAD. Mito Yoruba Transcrito de Paul A. Schroeder em Tomás Gutiérrez Alea. The Dialectics of a Filmaker. Nueva York: Routledge, 2002.

SARMENTO, R. "A narrativa na literatura e no cinema". In: Revista Travessias v. 6, n. 1. Cascavel-PR: Unioeste, 2012, pp. 5-23. Disponível em: http://erevista.unioeste.br/index.php/travessias/article/viewFile/6235/4830 Acessado em: 26 abr 2017.

SCHROEDER, P. A. Tomás Gutiérrez Alea. The Dialectics of a Filmaker. New York: Routledge, 2002

SOTOLONGO, A. G. "Tientos y diferencias de la Guantanamera compuesta por Julián Orbón. Política cultural de la revolución cubana de 1959”. In: Cuadernos de Música, Artes Visuales, Artes Escénicas 2. Bogotá: Pontificia Universidad Javeriana, Abril 2006-Septiembre 2006, pp. 146-175.

WALSH, C. La interculturalidad en la educación. Lima: Ministerio de Educación, 2005.

WALSH, C. "La interculturalidad y la educación básica ecuatoriana: Propuestas para la reforma educativa". In: Procesos. Revista Ecuatoriana de Historia 12, 1998, pp.119128.

Recebido em 27 de fevereiro de 2019

Aceito em 14 de abril de 2019 